\title{
Seven More Views on Intelligent Design
}

Moorad Alexanian

Citation: Physics Today 55, 9, 10 (2002); doi: 10.1063/1.4796836

View online: http://dx.doi.org/10.1063/1.4796836

View Table of Contents: http://physicstoday.scitation.org/toc/pto/55/9

Published by the American Institute of Physics

\section{Articles you may be interested in}

Seven More Views on Intelligent Design

Physics Today 55, 12 (2007); 10.1063/1.4796844

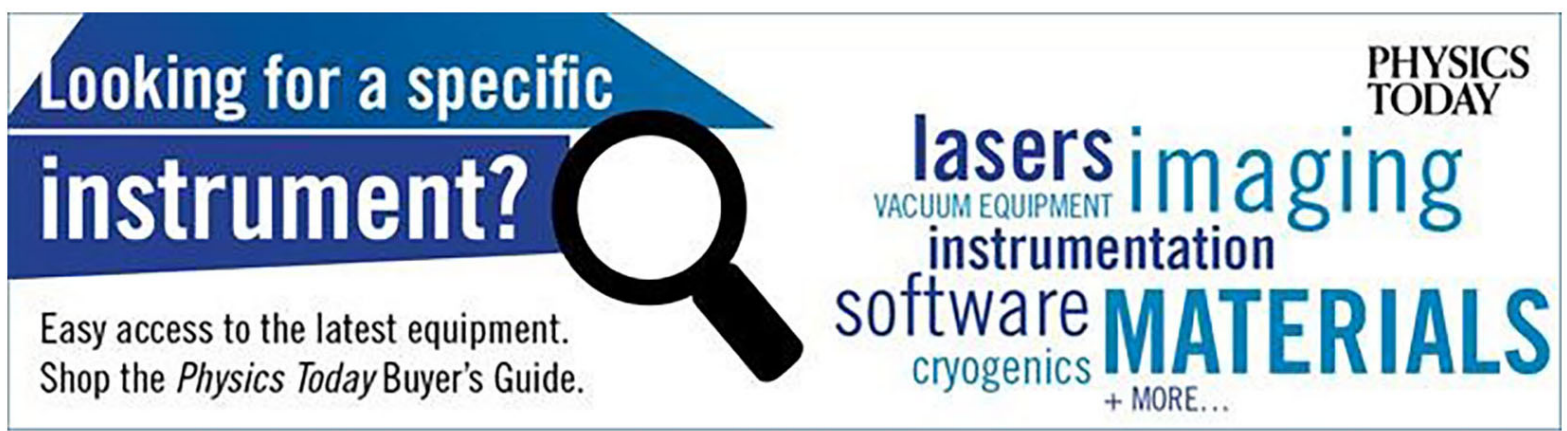




\section{Seven More Views on Intelligent Design}

$\mathrm{M}$ ano Singham makes several valid points about the role of philosophy in demolishing the intelligent design position (PHYSICS TODAY, June 2002, page 48). However, his final and most provocative point concerning the irrelevance of truth to science is not well-taken. In a human-based philosophy devoid of deity, "truth" simply means conformance of human mental contents, specifically concepts and propositions, to reality. Truth that requires omniscience and infinite accuracy with no contextual delimiters is a pseudoconcept that has no referent in the real world. By using "truth" only in that way, the author implicitly grants the creationists' premise that such a pseudoconcept has meaning. Singham's final point is only provocative or meaningful if the reader falls into the trap of thinking that that usage of "truth" does have meaning.

Humans constantly are discovering truths about the world, some of them comprehensive enough to constitute a scientific theory. A truth is contextual: It refers to a specific domain, a specific level of measurement accuracy, and the like. Newtonian physics was true when created and is true today. It was constructed and tested within a context of objects having a certain range of speeds and of measurements having a certain degree of accuracy; within that domain, it continues to be a true theory. Special relativity is true within a more extended context, and has led to new and broader conceptual understanding. However, special relativity in no way invalidates Newtonian physics within the latter's contextual domain.

"Science" has two meanings. It is a valid methodology that can generate both false and true theories; that some theories are found to be false

Letters and opinions are encouraged and should be sent to Letters, PHYSICS TODAY, American Center for Physics, One Physics Ellipse, College Park, MD 20740-3842 or by e-mail to ptletter@aip.org (using your surname as "Subject"). Please include your affiliation, mailing address, and daytime phone number. We reserve the right to edit letters. and are ultimately rejected is a vindication, not a criticism, of the method. Science also refers to an accumulating body of contextually true statements and theories about aspects of the world; the "truth" and the "validity" of these theories are synonymous. The value of science as a methodology lies strictly in the fact that it is an extremely successful means of arriving at, and expanding, true theories about the world.

RALPH LINSKER

(rlinsker@hotmail.com) Millwood, New York

$\mathrm{B}$ oth essays on intelligent design make good points. But I take exception to Mano Singham's reduction of the scientific quest to the mere process of answering "the immediate questions of interest to scientists," as opposed to seeking some truth. That reduction is as misguided as it is dangerous; it devalues science by placing it at the same level as social criticism and is essentially a repetition of the muddleheaded postmodernist arguments.

Granted, to a certain extent, the point is obviously true for some of the minor scientific theories that are in debate at any one time. But it completely fails to account for the major theories and advances. Were Johannes Kepler and Galileo simply engaged in some kind of inconsequential quest to answer the fashionable questions of their time? Did they discover some truth about planetary motions, or did they simply answer those questions to please the sensibilities of their contemporaries? Was Charles Darwin similarly engaged in a quest for some truth or for some fashionable theory? And where would Singham place the present search for extraterrestrial life? Is that also merely a question of present interest to scientists, or is it a quest after some momentous truth that can change us forever? Pronouncements such as "to be valid, science does not have to be true" merely serve to demonstrate how far common sense can be confused by words.

Revolutions in science are ultimately revolutions in how we see ourselves as humans, so the progress of science is, to a large extent, the progress of humanity. That is the core fact that creationists and postmodernists find so difficult to accept. Although they start from different premises, both groups have a need to reduce science to an enterprise that has only some relative value within its own limited circle of practitioners. When they have accomplished that, they can promulgate their own views - free of evidentiary supportas if those views were equivalent to what science has to offer.

So, although Singham's essay appears to be supportive of science, I submit that science would be better off without such support.

Pantazis Mouroulis (pmouroulis@surfree.com) Glendora, California

$\mathrm{M}$ ano Singham's Opinion article "Philosophy Is Essential to the Intelligent Design Debate" emphasizes both the importance of "the demarcation problem"-that is, the unambiguous distinction of science from nonscience-and the nature of "origins science."

Science deals with the physical aspect of reality; its subject matter is data that, in principle, can be collected solely by physical devices. If physical devices cannot measure something, then that something is not the subject matter of science. Of course, the whole of reality encompasses more than the physical.

Physics is the prototype of experimental science, which yields laws of nature based on data collected from repeatable experiments. In contrast, origins science is more akin to forensic science, because it deals with unique, nonrepeatable events. Nonetheless, for origins science to qualify as science, extant evidentiary data must also be collectible by physical devices.

Human consciousness and reasoning summarize all physical data into laws and create the mathematical theories that lead to predictions. However, the human element that creates the theories is totally absent from the laws and theories themselves. Accordingly, human consciousness and rationality are outside the bounds of science since they cannot be detected by purely physical devices and can only be "detected" by the self in humans. 
Unraveling the mysteries of nature requires conscious, intelligent beings. But no humanly conceived theory of nature, however complete, can ever encompass all that exists or the creation process that brought everything into being. This ontological problem is best answered by supposing the existence of a Creator, which must be conscious and intelligent to an infinitely higher degree. I believe this idea is the underlying rationale for advocates of intelligent design to infer an Intelligent Designer.

Human reasoning cannot avoid the fundamental question of origins, which is outside the purview of science. John Wheeler (PHYSICS TODAY, May 2002, page 28) said it best: "Philosophy is too important to leave to the philosophers, and I had better get busy on the most important question: How come existence?"

Moorad ALEXANiAN (alexanian@uncw.edu) University of North Carolina at Wilmington

CINGHAM REPLIES: Scientific knowl$\checkmark$ edge is the most powerful and reliable source of knowledge that we have. Naturally, we ask why that is so. The response that it provides us with true information about the world is strongly entrenched in the scientific community as an obvious truth. Predictably, then, challenging this assertion generates objections similar to those raised by Ralph Linsker and Pantazis Mouroulis.

Is there anything intrinsic in the subject matter or methods of science that justifies the belief that science is progressing toward the truth? Historians, philosophers, and sociologists of science have investigated this question; they have looked at how science is practiced and how scientific communities form, operate, arrive at consensus views, and make judgments about theories. What emerges is that the case for "truth" is hard to sustain (see references 2-6 and 9 in my original article). This is not some recent postmodern idea, as Mouroulis implies. The earliest substantive critique originated in 1906 with Pierre Duhem $;{ }^{1}$ his thesis has since withstood spirited challenges. ${ }^{2}$

The idea that advances in scientific knowledge are not inexorably leading to the truth may strike many as weakening the case for science against its critics in ID. I believe that the converse is true and that the admittedly limited view of scientific knowledge that I have advocated-as being useful, predictive, and natura- listic, but not necessarily true-completely undermines the case for the inclusion of ID in the scientific framework. But I don't espouse this view in order to oppose ID; it is a mistake to define science just to use that definition as a weapon in ideological wars. I arrived at my views regarding the nature of science long before ID came onto the scene, because I found the research of historians and philosophers of science to be very persuasive.

Those who hold the more expansive view that science is revealing the truth about nature must be prepared to defend their position with more robust examples and arguments than those usually offered. Linsker wants to restore the concept of truth by limiting the domain of applicability of theories and cites the relationship between Einsteinian and Newtonian dynamics. The weaknesses of that oft-quoted argument were highlighted a long time ago. ${ }^{3}$

The personal motivations of individual scientists are also not at issue. I have no doubt that most scientists, not just the ones 
Mouroulis names, see themselves as seeking some fundamental truth about the universe. But believing does not make it so. The search for truth may be a mirage, an illusion. A mirage can serve a very useful purpose by encouraging people to move forward and make real progress; the search for truth may play this role in science and may have led to some of its spectacular successes. (Incidentally, I applaud Mouroulis for decrying views that are "free of evidentiary support." But where is the evidentiary support for his own assertions?)

Moorad Alexanian puts forth another popular view: that a reality exists, apart from the physical one, "which cannot be detected purely by physical devices," and states as examples that "human consciousness and rationality are outside the bounds of science." This view may or may not be true, but what is the evidence for it? How would we know what is and is not part of physical reality? Neuroscientists and other brain researchers explore the very questions that, according to Alexanian, lie beyond physical reality. Are they operating outside science?

We cannot arbitrarily prescribe what science is. We can only infer its characteristics by examining how, in actual practice, its knowledge is created. The work of historians, philosophers, and sociologists of science, although not necessary for the practice of science, become important when dealing with claims such as ID.

\section{References}

1. P. Duhem, The Aim and Structure of Physical Theory, P. Wiener, trans., Princeton U. Press, Princeton, N.J. (1954).

2. S. G. Harding, ed., Can Theories Be Refuted? Essays on the Duhem-Quine Thesis, D. Reidel, Boston (1976).

3. T. Kuhn, The Structure of Scientific Revolutions, U. Chicago Press, Chicago (1970), chap. 9

$$
\begin{array}{r}
\text { MaNo SinghaM } \\
\text { (mxs24@po.cwru.edu) } \\
\text { Case Western Reserve University } \\
\text { Cleveland, Ohio }
\end{array}
$$

A s I scanned through the June A2002 issue of PHYsics TODAY, the Opinion articles on intelligent design caught my eye. I had read a couple of books on the subject and had thought the material interesting. Because the title said "two views," I guessed that there would be two opposing views like I typically see in newspaper editorials. Instead, when I read the articles, I found that both oppose the idea of intelligent design.
Here is my complaint: It's great to have opinion articles on a subject, especially if there is controversy or unresolved issues, but give both sides airtime. I typically disagree with one side or the other when two opposing opinions are expressed. But let's have both. As a scientist and engineer, I was expecting this. Usually, plenty of people on either side of an issue are willing to write a short article defending their side. Did you try to get one from both sides?

Claud E. LaCY Painted Post, New York

[We did not. PHYSICS TODAY's goal is to inform our readers about science and its place in the world, not about alternatives to science. THE EDITORS]

Twas disappointed to see that your Opinion articles on intelligent design were, in fact, two negative views of the controversial theory. I expected a more balanced approach from your magazine. If, as Adrian Melott asserts, "adherents are engineers, doctors-and even physicists," then it would have been appropriate to have a counterpoint from a scientist or doctor presenting a positive view for ID.

Furthermore, I thought the negative views, particularly those of Melott, to be more personal opinion than scientific refutation. Even the title of Melott's article-_Intelligent Design Is Creationism in a Cheap Tuxedo"-is, frankly, a cheap shot, and Melott distorted the views of people espousing ID. I have read Michael Behe's book Darwin's Black Box (Free Press, 1996) and Michael Denton's book Evolution: A Theory in Crisis (Adler \& Adler, 1986). Both authors make some strong, some weak, and some erroneous arguments. However, nowhere in either book did I find any indication that "geology and physics are within [ID's] blast zone." Denton, for example, clearly recognizes geologic time and the antiquity of fossils. For Melott to suggest that geology and geologic time are targets of ID indicates either that he has not read these books or that he is intentionally misrepresenting ID.

JAMES C. AdAMSKI (jimadamski@msn.com) Orlando, Florida

WELOTT REPLIES: I agree with IJames Adamski that the title of my piece is a cheap shot. A cheap shot is exactly appropriate with respect to ID. I agree that I wrote an opinion piece, not a scientific refuta- 
tion: See the references. It is also true that Michael Behe, Michael Denton, and others are careful to restrict their attacks to evolution. This is part of the "Big Tent" strategy to unify old-Earth, young-Earth, and other kinds of creationists while splitting the scientific community. Phillip Johnson, another IDist, is careful in his presentations not to offend young-Earthers: He maintains that the issue of Earth's age isn't important. What is most revealing, letters to the editor seen here and in Ohio have shown considerable blending of ID rhetoric with issues that impact geology and cosmology.

In his book No Free Lunch: Why Specified Complexity Cannot Be Purchased without Intelligence (Rowman \& Littlefield, 2002), William Dembski has invented a "conservation of information" law. This is unsupported new physics that is not treated as a hypothesis. He reports that the theory of inflation is explanatory but does not possess "independent evidence for its existence." The past several years have seen well-publicized experimental data confirming the extreme flatness of cosmological space and a nearly scale-invariant spectrum of density perturbations, both key predictions of inflation. There are also data that suggest the universe may be entering a new inflationary expansion. Dembski is either ignorant or has selectively deleted parts of existing physics. The preceding are but two examples of the "blast zone," drawn from ID's leading "design theorist."

Adamski and Claud Lacy both fall prey to the fairness fallacy; Lacy even mentions newspapers as a positive counterexample. One of the reasons the formulation of public policy encounters such terrible problems is that newspapers present "both sides" on matters of evidence as if they were matters of opinion, even when the evidence is strongly one-sided. This practice gives the public the impression of a serious scientific controversy. A fair representation of the views of working biological researchers should contain 2 or 3 ID advocates for about 10000 presentations opposing it. Thus, having two essays opposed to ID creationism, with none supporting it, as seen in the June issue of PHYsICS TODAY, is entirely appropriate.

Adrian L. Melott

(melott@kusmos.phsx.ukans.edu) University of Kansas Lawrence
A fter I read the Opinions by Adrian A Melott and Mano Singham, it occurred to me that ID is not only bad science but it's bad religion too. Such a "god of the gaps" as postulated by ID only becomes smaller with time as science moves on and solves mysteries that were formerly "explained" as miracles. Unfortunately, the proponents of ID blur the distinction between logos and mythos, ${ }^{1}$ between asking how we came to be and why we came to be. Arguably, humans need both logos and mythos to make sense of the world; both questions deserve our profound attention.

\section{Reference}

1. K. Armstrong, The Battle for God, Ballantine, New York (2001).

Megan Donahue (donahue@stsci.edu) Space Telescope Science Institute Baltimore, Maryland

$T$ he Opinion pieces by Adrian Melott and Mano Singham make clear the scientific and philosophical problems with the intelligent design movement and with attempts to insert ID into public-school science curricula. Moreover, the ideas of ID proponents are also in conflict with the views of many theologians who are engaged in dialogue between science and religion.

The notion that science should invoke supernatural causes to explain currently puzzling phenomena such as the origin of life is popular but theologically naïve. Discussions of divine action by participants in today's science-theology dialogue ${ }^{1}$ are generally in accord with the dictum of Dietrich Bonhoeffer, a Lutheran theologian hanged by the Nazis in 1945: "We are to find God in what we know, not in what we don't know." 2 God is active in the world through the natural processes that science studies. This is not an entirely modern idea. In Genesis 1, God is pictured as commanding the earth and the waters to bring forth living things. Many teachers of the early church understood that to mean that God had given the materials of the world the ability produce life when God willed it. ${ }^{3}$

The contents of science curricula must, of course, be argued for on scientific grounds. But those engaged in public debates about science education would do well to realize that ID proponents are out of touch with mainstream work at the science-theology interface.

continued on page 82 
relatively larger number of women at junior levels than in senior positions, as compared with men

- the cumulative negative effect of numerous minor obstacles in women's career paths

\section{References}

1. See, for example, I. G. Barbour, Religion and Science: Historical and Contemporary Issues, HarperSanFrancisco, San Francisco, Calif. (1997); N. Murphy, G. F. R. Ellis, On the Moral Nature of the Universe: Theology, Cosmology, and Ethics, Fortress Press, Minneapolis, Minn. (1996); J. Polkinghorne, Science and Providence: God's Interaction with the World, New Science Library, Boston, (1989).

2. D. Bonhoeffer, Letters and Papers from Prison, enlarged ed., Eberhard Bethge, ed., Macmillan, New York (1972), p. 311.

3. E. Messenger, Evolution and Theology, Macmillan, New York (1932).

GEORGE L. MURPHY (gmurphy@raex.com) Trinity Lutheran Seminary Columbus, Ohio

\section{Sexism Still an Obstacle for Women Scientists}

We read with interest and empathy about the first International Conference on Women in Physics, held in Paris in March (PHYsICS TODAY, May 2002, page 24). Many of the points raised in the article coincided with those expressed by participants at a December 1997 meeting held in Bangkok, Thailand, and sponsored by the World Meteorological Organization, on the participation of women in meteorology and hydrology. ${ }^{1}$ Like physics, these professions suffer from a gross underrepresentation of women. A 1996 survey of WMO member nations found that, on average, only 1 in 5 meteorologists and hydrologists in the responding nations was a woman. ${ }^{1,2}$ In the US, the figure was only about 1 in $10 .^{3}$

Both meetings expressed common themes:

- the similar challenges facing women scientists from different countries

- the need for culturally sensitive solutions to address the underrepresentation of women in science

- the larger proportion of younger women students and professionals compared with older professionals, which may indicate either a "leaky pipeline" or a trend toward greater gender balance

the difficulty of breaking through the glass ceiling, as shown by the

Tfind it interesting that the article con advanced physics in high schools and the article on women in physics appeared in the same issue. If my experience is any indication, the lack of women in physics is linked to the problems female students encounter in high school.
My high school offered AP calculus. I started high school in the honors math program. But I didn't continue, in part because one of my teachers would have been a man well-known for sleeping with female students. When he was finally arrested for sexual misconduct with a minor, I knew I had made the correct decision. What message does it send to young women when a teacher sleeps with students, the whole school knows, and no one does anything until a student reports it more than a decade later?

Moreover, when I told my highschool guidance counselor that I wanted to take physics, she said I shouldn't, because physics is hard. It angered me at the time, but I was going to be a music major then. The same woman advised my brother, a much worse student than I, to major in engineering in college. Such early experiences with sexism in the sciences are very discouraging to young girls. It is important to rein in sexist teachers in primary and secondary education.

Despite my high-school experiences, I finally discovered that my true calling is physics, and I'm in my fourth year at Colorado State University. I know I've had it much easier than women even a generation before me, but sexism is not gone yet. It is still tacitly accepted in higher education-especially in the sciences-even though equality may receive lip service.

An acquaintance of mine went to her organic chemistry teacher for help and was told, "Sometimes men just get it better than women." I overheard another faculty member making a joke about how he wouldn't help one of his male students unless that student brought in his attractive girlfriend. In light of the many hardships women have had to endure in the past, comments like that just aren't funny.

Discrimination against women still exists-it's just more subtle than it used to be. Attracting more women to physics will require confronting the latent sexism that remains in the field.

Name Withheld at Editors' Request

World Meteorological Organization Geneva, Switzerland 